\title{
Gender and Stress in Predicting Depressive Symptoms Following Stroke
}

\author{
Carolyn M. Mazure ${ }^{a, b}$ Andrea H. Weinberger ${ }^{a-c}$ Brian Pittman $^{a} \quad$ Igor Sibon $^{d, e}$ \\ Joel Swendsen ${ }^{e, f}$ \\ ${ }^{a}$ Department of Psychiatry, ${ }^{b}$ Women's Health Research at Yale, Yale University School of Medicine, New Haven, \\ Conn., 'Cancer Prevention and Control Research Program, Yale Cancer Center, New Haven, Conn., USA; ${ }^{\mathrm{d}} \mathrm{CHU}$ \\ University of Bordeaux, Bordeaux, 'University of Bordeaux, National Center for Scientific Research, Bordeaux, \\ ${ }^{\mathrm{f}} \mathrm{EPHE} /$ La Sorbonne, Paris, France
}

\section{Key Words}

Stroke $\cdot$ Depression $\cdot$ Gender $\cdot$ Stress

\begin{abstract}
Background: Post-stroke depression (PSD) is associated with poor clinical and functional outcomes, and women are likely to experience PSD more than men. Although stress is related to depression, and women report greater emotional reactivity to stressful life events, the link between stress and gender is yet to be examined relative to PSD. Further, electronic momentary assessment (EMA), a mobile technology, has not been used to assess stressful life events and PSD in real time and in the natural environments of daily life. The purpose of the current study was to examine gender differences in the relationship of stress and PSD using EMA. Methods: Individuals admitted to the Stroke Center at the University of Bordeaux were contacted for participation in a prospective study of symptoms and experiences in daily life using ambulatory monitoring. Forty-three post-stroke patients ( $47 \%$ female) completed electronic assessments of life events, perceived stress, and depressive symptoms (i.e., sad mood, anhedonia, fatigue, concentration difficulties, appetite change, negative thoughts, hopelessness) during their
\end{abstract}

daily life for one week. Patients also completed a clinicianadministered standardized depression scale at baseline and three-month follow-up. Results: Using EMA, participants responded to $83.7 \%$ of the electronic interviews for a total of 1,140 observations across diverse daily life contexts. Stressful events of any degree of negativity were reported at over one-third (37.3\%) of all EMA assessments. The severity of depressive symptoms as assessed in daily life through EMA was greater in women following stroke than in men. Further, there was a significant association between EMA-assessed depressive symptoms and daily life stress for women, but not men. This association was due primarily to three specific depressive symptoms: sad mood, fatigue, and appetite change. No difference was observed between men and women in standardized depression assessments administered during clinic visits at baseline or three-month followup. Conclusions: Greater reactivity to stressful life events and a link between stress reactivity and depressive symptoms were found in female as compared to male post-stroke patients. Gender differences in depressive symptoms were identified using EMA data collected during daily life as con-

The current work was conducted at the University of Bordeaux.

\section{KARGER}

E-Mail karger@karger.com

www.karger.com/ced (c) 2014 S. Karger AG, Base

1015-9770/14/0384-0240\$39.50/0
Carolyn M. Mazure, $\mathrm{PhD}$

Norma Weinberg Spungen and Joan Lebson Bildner Professor of Psychiatry and Psychology, Yale University School of Medicine

135 College Street, Suite 220, New Haven, CT 06510 (USA)

E-Mail carolyn.mazure@yale.edu 
trasted with the use of a standard assessment during clinic visits. Mobile technologies may help to identify important real-time behaviors and symptoms that are not observable by standard clinical assessments employed at regular clinic visits. Further, future research should examine the overall and gender-specific benefits of stress-based interventions to reduce the risk of PSD for adults.

(c) 2014 S. Karger AG, Basel

\section{Introduction}

Stroke is a leading cause of death and disability around the world for both men and women $[1,2]$ and identifying its prognostic indicators has emerged as a major objective for clinical research. Among the diverse medical and psychological factors examined in this population, depression has been shown to be among the more consistent predictors of course and outcome due to its association with poor functional recovery and greater mortality [36]. Post-stroke depression (PSD) is highly frequent, occurring in up to half of patients one month after stroke [3, 7] and with continued high rates one year later [8]. For these reasons, understanding the risk factors associated with PSD is essential for determining preventive interventions that can reduce morbidity rates and promote better functional outcomes.

Numerous epidemiologic surveys of nationally representative samples in the United States have demonstrated that women have twice the risk of experiencing an episode of depression than men [9-11], and World Health Organization assessments of depression worldwide support higher rates of depression in women versus men [12]. While the prevalence of stroke is similar for either gender [13], the female gender is associated with a greater likelihood of PSD in the majority of studies that have included gender as a factor in analyses [3, 7]. Seeking the potential mechanisms underlying these differences, several investigations have pointed to the role of stress and emotional reactivity. Stress is closely linked to the onset of depression [14-16], and adults with depression report greater emotional $[17,18]$ and physiological $[19,20]$ responses to stress. Importantly, women demonstrate greater emotional reactivity to negative events than men, as well as experience more prolonged negative emotions following negative life events [21,22]. Despite the existing literature documenting that these factors play a role in the etiology and/or severity of depression, the interaction of gender and stress is yet to be examined relative to $\mathrm{PSD}$.

Depressive Symptoms Following Stroke
The limited research on this topic may be explained in part by the methodological barriers that have prevented the examination of how stress may influence depressive symptoms. In particular, most laboratory- or hospitalbased protocols are limited to the retrospective assessments of stress or to the assessments of mood either at one time point during a clinic visit or averaged over substantial periods of time. It is therefore difficult or impossible to characterize the highly dynamic interplay of stressful events and symptoms as they occur naturally in daily life. Advances in mobile technologies, such as Ecological Momentary Assessment (EMA), have permitted researchers to overcome these barriers of time and context by following patients in real-time and in the natural environments of daily life [23]. Recent studies have demonstrated the validity of this approach in patients who have experienced a stroke $[24,25]$ and have shown that emotional reactivity to stressful life events during the period immediately following stroke is associated with depression severity three months later [24]. However, these investigations have not examined gender differences in mood reactivity, nor how these effects may be moderated by other clinical risk factors. The present investigation examined these issues using EMA over a one-week period in patients following stroke. The specific goal of this study was to examine gender differences in the relationship of stress and PSD.

\section{Materials and Methods}

\section{Patients}

Sixty-four individuals admitted to the Stroke Center at the University of Bordeaux were contacted to participate in a prospective study of symptoms and experiences in daily life using ambulatory monitoring. Patients were continuously enrolled based on eligibility criteria. Forty-eight individuals (75\% of the contacted sample) agreed to participate. Inclusion criteria were ischemic or hemorrhagic stroke diagnosed by a neurologist based on clinical and neuroradiological data (MRI). Exclusion criteria were a personal history of major depressive disorder, dementia, severe aphasia, and visual or motor handicaps preventing adequate use of the ambulatory monitoring device. The mean age of the sample was 59.5 years $(\mathrm{SD}=$ 12.8 ), and $47 \%$ were female. In this sample, 3 patients had a hemorrhagic stroke in the left basal ganglia, the frontal lobe or the parietal lobe. The remaining 45 patients experienced ischemic stroke located in the left $(n=15)$ or right $(n=17)$ middle cerebral artery, the vertebro basilar territory $(n=11)$, and the left anterior $(n=1)$ and posterior $(n=1)$ cerebral artery. Analyses for the present report are based on data from 43 participants who met the minimum EMA criteria of providing both within and between-day reports (i.e., at least 6 valid assessments; $67 \%$ of the contacted sample). On average, these individuals responded to $83.7 \%$ of the electronic interviews (or a mean of 29 out of the 35 possible assessments, $\mathrm{SD}=17.4$ ).

Cerebrovasc Dis 2014;38:240-246 
Procedure

This investigation was approved by the ethics review board of the University of Bordeaux (CPP). All patients provided written consent to participate, and the study methods have been previously described in detail [25]. In summary, participants completed a 45-minute training session on how to operate and complete electronic interviews on a personal digital assistant (PDA). The mean delay between stroke occurrence and the first electronic interview was 5.4 days $(\mathrm{SD}=4.0)$. PDAs were programmed using a modified version of the Purdue Momentary Assessment Tool, version 2.1.2. A validation study [25] conducted in this sample demonstrated feasibility of computerized ambulatory monitoring in stroke patients $(75 \%$ of contacted patients agreed to participate and recruited individuals completed over $80 \%$ of programmed interviews), as well as strong concurrent validity between clinic-based measures and daily life assessments. Specifically, although the sensitivity for identifying real-time mood changes in reaction to stressful events may be greater with EMA, this study demonstrated the concurrent validity of EMA relative to traditional clinical measures. Participants were given PDAs to carry with them for the 7-day monitoring phase, each programmed to administer 5 electronic interviews per day: between 9:00 a.m. to 11:00 a.m.; 11:00 a.m. to 2:00 p.m.; 2:00 p.m. to 5:00 p.m.; 5:00 p.m. to 8:00 p.m.; and 8:00 p.m. to 10:00 p.m. All individuals were instructed to complete the interviews independently. The PDA program permitted 15-minute response periods and all data entries were time stamped. Assessment times were also tailored individually to accommodate typical sleep and wake schedules. In addition to EMA assessments, participants were also administered a measure of clinical depression [25] at baseline and again 90 days later.

\section{Clinical Measures}

The 17-item Hamilton Depression Rating Scale (HAMD; [26]) was used to assess symptoms of depression at baseline and at three month follow-up. The HAMD is a clinician-administered measure that assesses mood, somatic, and cognitive symptoms of depression. HAMD scores can range from 0 to 54, with scores above 7 indicating a cut-off for mild symptoms of depression. The validity of the HAMD has been previously established with adults in the general population [27] and stroke patients [28]. Further, the HAMD has satisfactory inter-rater and test-retest reliability [29, 30].

\section{EMA Measures}

The EMA electronic assessments collected patient self-reports of activities, contexts, symptoms and daily life events. Seven of the symptoms present among DSM-IV criteria for depression were individually assessed at each electronic interview based on 7-point Likert scales: sad mood, anhedonia, fatigue, concentration difficulties, appetite change, negative thoughts, and hopelessness. These seven items were also summed to provide a Global Index of Depression. Each depressive symptom was assessed by asking participants to evaluate their current state at the moment of the EMA electronic assessment. Participants were then asked to identify daily life events that occurred since the last electronic assessment (spanning a three-hour period, on average), describe the one event that had the greatest impact, and rate the event on a 7-point Likert scale from 'extremely positive' to 'extremely negative'. Negative event severity was measured on a continuum to reflect all events rated as having no or neutral impact (0), a mildly negative impact (1), a moderately negative impact (2), or a severely negative impact (3).

\section{Statistical Analyses}

To account for the hierarchical structure of the data, linear mixed models were used to assess gender differences in the association between negative event severity and depressive symptoms. In these models, each symptom represented, in turn, the dependent variable; gender and stress represented fixed effects, and both subjects and subjects nested within days represented random effects. All main and interactive effects were tested. The best fitting variance-covariance structure was assessed by information criteria. All analyses were conducted using SAS, version 9.3 (Cary, N.C., USA).

\section{Results}

Participants demonstrated considerable variance in stroke and depression severity at both baseline and follow up but with average severity levels within the mild range (table 1). Concerning EMA monitoring, participants generated a total of 1,140 observations across diverse daily life contexts. Stressful events of any degree of negativity were reported at over one-third $(n=420,37.3 \%)$ of all EMA assessments. The continuous stress index reflected 727 events, of which 307 (42.2\%) were judged as having no impact, $173(23.8 \%)$ as mildly negative, $130(17.9 \%)$ as moderately negative, and $117(16.1 \%)$ as severely negative.

\section{Depression Severity by Gender and Stress}

A first series of analyses examined gender differences in depression scores as assessed using the HAMD. No differences were observed between men and women for HAMD scores at baseline $\left(\mathrm{t}_{39}=0.07, \mathrm{p}=0.94\right)$ or at the three-month clinic follow-up visit $\left(\mathrm{t}_{41}=0.45, \mathrm{p}=0.66\right)$.

Daily life depressive symptoms assessed through EMA were then examined relative to the potential main effects of gender as well as reports of daily life stress. In contrast to the standardized HAMD, the severity of depressive symptoms as measured by the EMA Global Depression Index was greater in women than in men, $\mathrm{F}(1,475)=$ $3.99, \mathrm{p}=0.046$, and depression severity increased as a function of stress, $\mathrm{F}(3,475)=9.91, \mathrm{p}<0.001$. There was also a significant interaction between gender and stress, $\mathrm{F}(3,475)=2.93, \mathrm{p}=0.033$ with women, but not men, experiencing greater increases in depression severity as a function of increasing stress.

These effects were examined next using the specific DSM-IV symptoms of sad mood, anhedonia, fatigue, con- 
Table 1. Description of clinical and EMA variables

\begin{tabular}{|c|c|c|c|c|c|c|}
\hline & $\mathrm{n}$ & $\%$ & Mean & $\mathrm{SD}$ & Min & Max \\
\hline \multicolumn{7}{|l|}{ Sample characteristics $(n=43)$} \\
\hline Gender, female & 19 & $44.2 \%$ & & & & \\
\hline Age & & & 59.30 & 13.34 & 28 & 83 \\
\hline Stroke severity (NIHSS) & & & 2.03 & 2.77 & 0 & 11 \\
\hline Baseline depression (HAMD) & & & 7.39 & 4.47 & 0 & 21 \\
\hline Three-month follow-up depression (HAMD) & & & 8.26 & 5.35 & 1 & 21 \\
\hline \multicolumn{7}{|l|}{ EMA (observations $=1,140)$} \\
\hline Number of stressful events & 420 & $36.8 \%$ & & & & \\
\hline Negativity of events & & & 1.08 & 1.11 & 0 & 3 \\
\hline Sad mood & & & 2.47 & 1.50 & 1 & 7 \\
\hline Anhedonia & & & 4.28 & 1.59 & 1 & 7 \\
\hline Fatigue & & & 4.38 & 1.49 & 1 & 7 \\
\hline Concentration difficulties & & & 3.19 & 1.50 & 1 & 7 \\
\hline Appetite change & & & 2.59 & 1.88 & 1 & 7 \\
\hline Negative thoughts & & & 2.39 & 1.77 & 1 & 7 \\
\hline Hopelessness & & & 3.07 & 1.43 & 1 & 7 \\
\hline EMA Global Index of Depression & & & 22.30 & 6.08 & 7 & 42 \\
\hline
\end{tabular}

EMA = Ecological momentary assessment SD = standard deviation; Min = minimum scores; $\mathrm{Max}=$ maximum scores; NIHSS = National Institutes of Health Stroke Scale; HAMD = Hamilton Depression Rating Scale.

Table 2. Effects of gender and stress on symptoms present among DSM-IV criteria for depression

\begin{tabular}{|c|c|c|c|c|c|c|c|c|c|}
\hline Self-reported symptom & $\mathrm{df}_{\text {denominator }}$ & F value & $\mathrm{p}$ value & $\mathrm{df}_{\text {denominator }}$ & F value & $\mathrm{p}$ value & $\mathrm{df}_{\text {denominator }}$ & F value & $\mathrm{p}$ value \\
\hline Anhedonia & 474 & 0.11 & 0.74 & 474 & 13.23 & 0.001 & 474 & 1.47 & 0.22 \\
\hline Fatigue & 475 & 2.78 & 0.096 & 475 & 3.55 & 0.014 & 475 & 3.61 & 0.013 \\
\hline Concentration difficulties & 473 & 0.02 & 0.89 & 473 & 0.24 & 0.87 & 473 & 1.70 & 0.17 \\
\hline Hopelessness & 471 & 0.37 & 0.54 & 471 & 2.36 & 0.071 & 471 & 1.52 & 0.21 \\
\hline
\end{tabular}

For all symptoms numerator d.f. = 1, 3, and 3 for gender, stress, and interaction effects, respectively. Post-hoc tests reported in Results.

centration difficulties, appetite change, negative thoughts, and hopelessness (table 2) which comprise the EMA Global Depression Index. Of all symptoms, the most salient effects were observed for sad mood, with higher levels being experienced by women as compared to men, $\mathrm{F}(1,475)=$ $4.94, \mathrm{p}=0.027$, and with higher levels as a function of increasing stress, $\mathrm{F}(3,475)=8.47, \mathrm{p}<0.001$. A significant interaction, $\mathrm{F}(3,475)=5.06, \mathrm{p}=0.002$, was again observed between these two factors (fig. 1). While men did not experience increases in sad mood related to stress levels,
$\mathrm{F}(1,475)=0.74, \mathrm{p}=0.39$, a robust linear trend was observed among women, $\mathrm{F}(1,475)=36.5$, $\mathrm{p}<0.001$. In particular, women experienced greater emotional reactivity (i.e., greater sadness) than men at both moderate $\mathrm{F}(1$, $475)=5.26, \mathrm{p}=0.022$, and high $\mathrm{F}(1,475)=12.0, \mathrm{p}<0.001$, stress levels. At high levels of stress, women also experienced greater fatigue $\mathrm{F}(1,475)=6.64, \mathrm{p}=0.01$, and greater appetite change $\mathrm{F}(1,475)=8.22, \mathrm{p}=0.004$, compared to men. No interaction effects for gender and stress were observed for the other depressive symptoms. 
Fig. 1. Gender differences in mood reactivity to stressful events.

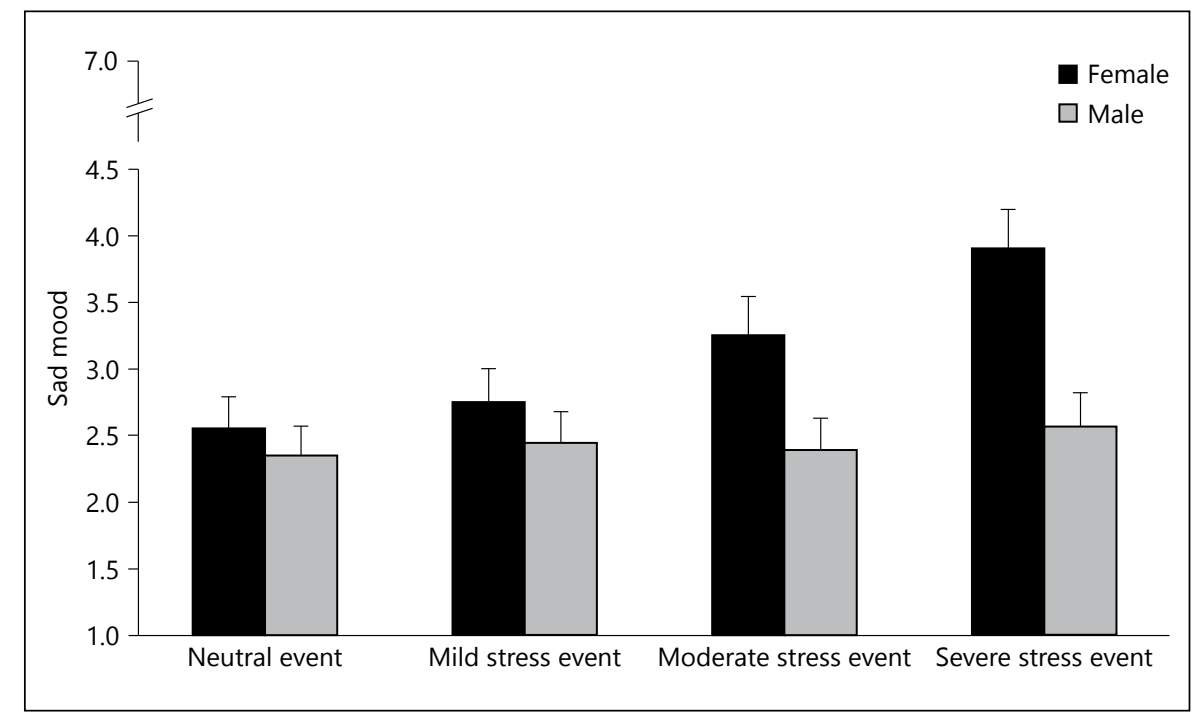

\section{Discussion}

The severity of depressive symptoms as assessed in daily life through EMA was greater in women post-stroke than in men. Moreover, women but not men reported increases in depressive symptom severity associated with stress. In particular, the association between depression and stress for women was reflected in symptoms of sad mood, fatigue and appetite change. Women who have experienced stroke are more likely to report $\operatorname{PSD}[3,7]$ and our EMA data support this finding. Women also generally show greater reactivity to stressful life events compared to men $[21,22]$. Our results demonstrate greater reactivity in women post-stroke, and a link between stress reactivity and depressive symptoms.

Contrary to the EMA real-time findings, no gender difference was found in depressive symptoms as measured by a standardized HAMD administered at baseline or follow-up clinic visits. While there is evidence for the general association of constructs examined by EMA and clinic-based measures [25], the current findings underscore important differences that can be observed according to the manner in which depression is assessed. In particular, the significant associations observed for EMA assessments suggest that common measures used at single points in time during clinic visits may not be sufficient to detect important gender differences in post-stroke depression occurring in real-time, and that alternative approaches such as EMA should be considered for the investigation or assessment of this disorder. The findings of this study also suggest that the use of mobile technologies reduces the influence of retrospective recall, increases ecological validity, and allows the closer study of dynamic behaviors as they happen in natural contexts $[23,31]$. Further, electronic methods of data collection have demonstrated high levels of compliance and validity for a wide range of patients with medical and psychiatric disorders $[25,32,33]$. Such monitoring can be used to detect changes in depression, emotional reactivity, functional impairment, and other outcomes targeted by interventions to reduce PSD and the long-term consequences of PSD.

Several limitations of the methodology should be considered when interpreting the findings. As the sample was screened to exclude those with a previous history of depression, the findings are most relevant to understanding new cases of PSD rather than recurrence of mood disorder. The selected sample can be considered to be in the mild-to-moderate range of stroke severity, and therefore, the findings cannot be generalized to more severely affected populations. While the analytic approach takes into account the within-subject correlation, both within and across days and adjusts for between-person differences in the manner that events were evaluated, the assessment of stress was based on the patient's subjective evaluations of event negativity. The moderate sample size may be insufficient for characterizing smaller but potentially important associations between stress and certain depressive symptoms that were not observed in the present sample. In addition, the lack of systematic assessment of clinical risk factors for stroke (e.g., smoking) prevents examination of potential moderation effects that may help identify individuals at the greatest risk for PSD. Fur- 
ther, the level of depression reported on the HAMD was moderately low although it was consistent with a recent investigation of PSD using the HAMD, which found lower depressive symptoms associated with PSD than major depression [34]. The lower level of symptoms for PSD relative to major depression may also be indicative of the importance of assessments that are done in the patients' natural environments in order to capture the full variability of symptoms and correlates of PSD. Finally, EMA was used only in the immediate period following stroke and not at the three-month follow-up. As the clinical manifestations of PSD have been shown to differ in the months that follow stroke [24], the repetition of EMA at different time periods may provide clearer information concerning the period of greatest differences by gender, stress, and other risk factors.

\section{Conclusions}

Stress has repeatedly been shown to be associated with depression $[15,16]$, particularly in women $[35,36]$. Our data in post-stroke patients are consistent with these findings. Although stress in daily life cannot be avoided, its effects can be moderated, for example, by external support and cognitive intervention strategies, to reduce depressive symptoms [37]. The current work suggests the potential importance of future work to determine the benefits of incorporating stress-reduction interventions in treatment plans post stroke, especially for women.

\section{Acknowledgments}

None.

\section{Sources of Funding}

Supported by NIH (RL5-DA024858, Dr. Mazure; P50DA033945 [ORWH, NIDA, \& FDA], PI: Dr. Sherry McKee); the State of Connecticut, Department of Mental Health and Addiction Services (Dr. Weinberger); a Centre National de la Recherche Scientifique (CNRS) ATIP award (Dr. Swendsen); and a grant from the French Neurovascular Society (Dr. Sibon).

\section{Disclosure Statement}

Drs. Mazure, Weinberger, Sibon, and Swendsen and Mr. Pittman report no conflicts of interest.

\section{References}

1 Mathers CD, Bernard C, Iburg KM, Inoue M, Ma Fat D, Shibuya K, et al: Global Burden of Disease in 2002: data sources, methods and results. Geneva: World Health Organization, 2003.

-2 WHO Task Force on Stroke and other Cerebrovascular Disorders: Stroke - 1989: recommendations on stroke prevention, diagnosis, and therapy. Report of the WHO Task Force on Stroke and other Cerebrovascular Disorders. Stroke 1989;20:1407-1431.

$\checkmark 3$ Kouwenhoven SE, Kirkevold M, Engedal K, Kim HS: Depression in acute stroke: prevalence, dominant symptoms and associated factors. A systematic literature review. Disabil Rehabil 2011;33:539-556.

$>4$ Pohjasvaara T, Vataja R, Leppavuori A, Kaste M, Erkinjuntti T: Depression is an independent predictor of poor long-term functional outcome post-stroke. Eur J Neurol 2001;8: 315-319.

5 Williams LS, Ghose SS, Swindle RW: Depression and other mental health diagnoses increase mortality risk after ischemic stroke. Am J Psychiatry 2004;161:1090-1095.

-6 Sibolt G, Curtze S, Melkas S, Pohjasvaara T, Kaste M, Karhunen PJ, et al: Post-stroke depression and depression-executive dysfunction syndrome are associated with recurrence of ischaemic stroke. Cerebrovasc Dis 2013;36: 336-343.

$>7$ Poynter B, Shuman M, Diaz-Granados N, Kapral M, Grace SL, Stewart DE: Sex differences in the prevalence of post-stroke depression: a systematic review. Psychosomatics 2009;50:563-569.

$>8$ Aben I, Verhey F, Strik J, Lousberg R, Lodder J, Honig A: A comparative study into the one year cumulative incidence of depression after stroke and myocardial infarction. J Neurol Neurosurg Psychiatry 2003;74:581-585.

-9 Kessler RC, McGonagle KA, Swartz M, Blazer DG, Nelson CB: Sex and depression in the National Comorbidity Survey. I: Lifetime prevalence, chronicity and recurrence. J Affect Disord 1993;29:85-96.

10 Andrade L, Caraveo-Anduaga JJ, Berglund P, Bijl RV, De Graaf R, Vollebergh W, et al: The epidemiology of major depressive episodes: results from the International Consortium of Psychiatric Epidemiology (ICPE) Surveys. Int J Methods Psychiatr Res 2003;12:3-21.

11 Hasin DS, Goodwin RD, Stinson FS, Grant BF: Epidemiology of major depressive disorder: results from the National Epidemiologic Survey on Alcoholism and Related Conditions. Arch Gen Psychiatry 2005;62:10971106.
12 Ferrari AJ, Charlson FJ, Norman RE, Patten SB, Freedman G, Murray CJ, et al: Burden of depressive disorders by country, sex, age, and year: findings from the global burden of disease study 2010. PLoS Med 2013; 10:e1001547.

13 Miniño AM, Murphy SL, Xu J, Kochanek KD: Deaths: Final Data for 2008. Hyattsville, MD: National Center for Health Statistics, 2011.

14 Mazure CM, Bruce ML, Maciejewski PK, Jacobs SC: Adverse life events and cognitivepersonality characteristics in the prediction of major depression and antidepressant response. Am J Psychiatry 2000;157:896-903.

15 Kessler RC: The effects of stressful life events on depression. Annu Rev Psychol 1997;48: 191-214.

16 Hammen C: Stress and depression. Annu Rev Clin Psychol 1997;1:293-319.

17 Bylsma LM, Taylor-Clift A, Rottenberg J: Emotional reactivity to daily events in major and minor depression. J Abnorm Psychol 2011;120:155-167.

18 de Rooij SR, Schene AH, Phillips DI, Roseboom TJ: Depression and anxiety: associations with biological and perceived stress reactivity to a psychological stress protocol in a middle-aged population. Psychoneuroendocrinology 2010;35:866-877. 
19 Palazidou E: The neurobiology of depression. Br Med Bull 2012;101:127-145.

20 Bao AM, Meynen G, Swaab DF: The stress system in depression and neurodegeneration: focus on the human hypothalamus. Brain Res Rev 2008;57:531-553.

-21 Husky MM, Mazure CM, Maciejewski PK, Swendsen JD: Past depression and gender interact to influence emotional reactivity to daily life stress. Cognitive Ther Res 2009;33:264271.

22 Johnson EI, Husky M, Grondin O, Doron J, Mazure CM, Swendsen J: Mood trajectories following daily life events. Motiv Emot 2008; 32:251-259.

-23 Shiffman S, Stone AA, Hufford MR: Ecological momentary assessment. Annu Rev Clin Psychol 2008;4:1-32.

24 Sibon I, Lassalle-Lagadec S, Renou P, Swendsen J: Evolution of depression symptoms following stroke: a prospective study using computerized ambulatory monitoring. Cerebrovasc Dis 2012;33:280-285.

-25 Johnson EI, Sibon I, Renou P, Rouanet F, Allard M, Swendsen J: Feasibility and validity of computerized ambulatory monitoring in stroke patients. Neurology 2009;73:1579-1583.
26 Hamilton M: A rating scale for depression. J Neurol Neurosurg Psychiatry 1960;23:56-62.

27 Knesevich JW, Biggs JT, Clayton PJ, Ziegler VE: Validity of the Hamilton Rating Scale for depression. Br J Psychiatry 1977;131:49-52.

28 Aben I, Verhey F, Lousberg R, Lodder J, Honig A: Validity of the beck depression inventory, hospital anxiety and depression scale, SCL-90, and Hamilton Depression Rating Scale as screening instruments for depression in stroke patients. Psychosomatics 2002;43: 386-393.

29 O'Hara MW, Rehm LP: Hamilton Rating Scale for Depression: reliability and validity of judgments of novice raters. J Consult Clin Psychol 1983;51:318-319.

30 Williams JB: A structured interview guide for the Hamilton Depression Rating Scale. Arch Gen Psychiatry 1988;45:742-747.

31 Piasecki TM, Hufford MR, Solhan M, Trull TJ: Assessing clients in their natural environments with electronic diaries: rationale, benefits, limitations, and barriers. Psychol Assess 2007;19:25-43.
2 Swendsen J, Ben-Zeev D, Granholm E: Realtime electronic ambulatory monitoring of substance use and symptom expression in schizophrenia. Am J Psychiatry 2011;168: 202-209.

33 Husky MM, Gindre C, Mazure CM, Brebant C, Nolen-Hoeksema S, Sanacora G, et al: Computerized ambulatory monitoring in mood disorders: feasibility, compliance, and reactivity. Psychiatry Res 2010;178:440-442.

34 da Rocha e Silva CE, Alves Brasil MA, Matos do Nascimento E, de Braganca Pereira B, Andre C: Is poststroke depression a major depression? Cerebrovasc Dis 2013;35:385-391.

35 Mazure CM: Life stressors as risk factors in depression. Clin Psychol 1998;5:291-313.

36 Maciejewski PK, Prigerson HG, Mazure CM: Sex differences in event-related risk for major depression. Psychol Med 2001;31:593604

37 Antoni MH, Lehman JM, Kilbourn KM, Boyers AE, Culver JL, Alferi SM, et al: Cognitivebehavioral stress management intervention decreases the prevalence of depression and enhances benefit finding among women under treatment for early-stage breast cancer. Health Psychol 2001;20:20-32. 